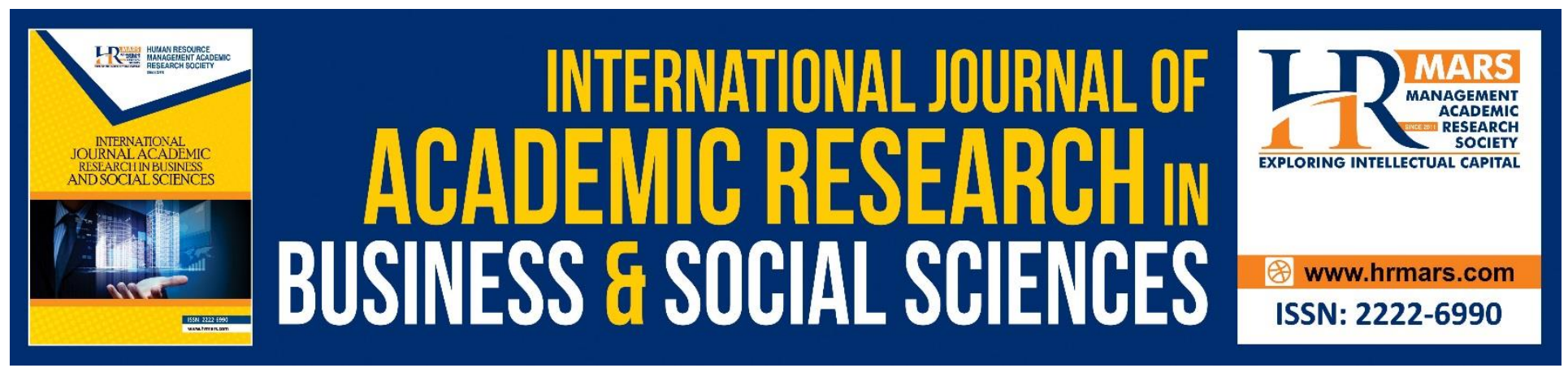

\title{
Exploring the Perspectives of Pre-University Students on Authentic Collaborative Writing Project
}

\author{
Keezrawati Mujan Yusuf
}

To Link this Article: http://dx.doi.org/10.6007/IJARBSS/v11-i14/8567

DOI:10.6007/IJARBSS/v11-i14/8567

Received: 11 November 2020, Revised: 10 December 2020, Accepted: 26 December 2020

Published Online: 25 January 2020

In-Text Citation: (Yusuf, 2021)

To Cite this Article: Yusuf, K. M. (2021). Exploring the Perspectives of Pre-University Students on Authentic Collaborative Writing Project. International Journal of Academic Research in Business and Social Sciences, 11(14), 199-210.

Copyright: @ 2021 The Author(s)

Published by Human Resource Management Academic Research Society (www.hrmars.com)

This article is published under the Creative Commons Attribution (CC BY 4.0) license. Anyone may reproduce, distribute, translate and create derivative works of this article (for both commercial and non-commercial purposes), subject to full attribution to the original publication and authors. The full terms of this license may be seen

at: http://creativecommons.org/licences/by/4.0/legalcode

Special Issue: Contemporary Business and Humanities Landscape Towards Sustainability, 2021, Pg. 199 - 210 http://hrmars.com/index.php/pages/detail/IJARBSS JOURNAL HOMEPAGE

Full Terms \& Conditions of access and use can be found at http://hrmars.com/index.php/pages/detail/publication-ethics 


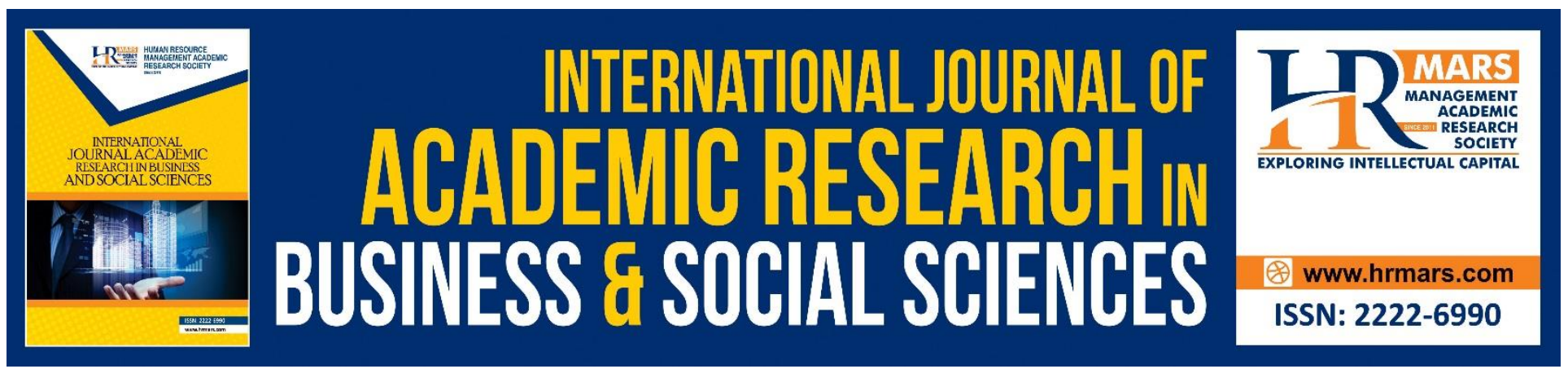

\title{
Exploring the Perspectives of Pre-University Students on Authentic Collaborative Writing Project
}

\author{
Keezrawati Mujan Yusuf \\ Faculty of Language and Communication, Universiti Malaysia Sarawak, 94300 Kota Samarahan, \\ Sarawak, Centre for Pre-University Studies, Universiti Malaysia Sarawak, 94300 Kota Samarahan, \\ Sarawak \\ Email: ykeezrawati@unimas.my
}

\begin{abstract}
The goal of pre-university programs is to prepare students for undergraduate studies. Therefore, the courses offered in centres of pre-university studies should cultivate higher level of independence and critical thinking which are needed by a university student. This paper explores the usefulness of authentic collaborative writing project to bridge the gap between secondary and tertiary studies. This qualitative study aimed to look into the perspectives of 10 students on the benefits and challenges of their group writing project where they had to publish a mini magazine that explores current social issues. The responses were collected through semi-structured interviews with each student. Generally, it was found that the students regarded the project positively as they were given a high level of autonomy in developing their magazine, which encouraged them to conduct extensive research, group discussion and peer assessment. However, the students noted that they experienced technical difficulties in designing and printing the magazine as it was an unfamiliar genre to them. Some students also commented that they encountered typical problems in group projects such as conflicting ideas and irresponsible group members. The findings have several pedagogical and research implications in pre-university language classrooms.
\end{abstract}

Keywords: Authentic Task, Collaborative Writing, Pre-University Studies, Writing Assessment

\section{Introduction}

Collaborative writing refers to the activity of composing together and sharing decision-making power between multiple authors to create a single written text (Allen et al., 1987). Apart from the final written text, the intended outcomes of collaborative writing also include the collective cognition of writers where they arrive at insights that they could not have arrived at on their own such as the acquisition of new lexicon and improved ways of idea expression (Storch, 2013). Thus, the process of writing which includes steps such as generating ideas, researching for information, planning, 
organising, drafting, revising and editing are just as important as the final product (Ong \& Maarof, 2013).

Collaborative writing is underpinned by Vygotsky's Social Development Theory. According to this theory, social interaction plays a fundamental role in the development of cognition (Vygotsky, 1978; Banaag et al., 2014). Vygotsky (1978) theorises that learners co-construct knowledge as they interact with their partners within the zone of proximal development (ZPD), the distance between learners' ability to perform a task under the assistance of a more knowledgeable other (MKO) and their ability to solve the problem independently. MKO is usually assumed to be limited to teachers or adults, but peers can also play the role of MKO as each learner brings his or her own skills, knowledge and abilities into the interaction. In the current research which studied a collaborative writing project, each member of the group acted as the MKO who contributed their individual strengths in the area where the other group members are weak at i.e. their ZPD, such as vocabulary, grammar and idea for the text.

Previous studies have shown that collaborative writing benefits students in multiple ways. Firstly, the process of collaborating requires the students to discuss their choice of language with their peers (Li \& Kim, 2016). They have to evaluate and justify their linguistic choices which can open to many language learning opportunities. Moreover, collaborative writing allows students to pool their linguistic resources which allow them to manage tasks that are more demanding, as opposed to individual writing where each student has to rely on their own knowledge (Scott \& de la Fuente, 2008). Scholars have also noted that collaborative writing improves language accuracy in terms of grammar and vocabulary (Storch, 2005).

The notion of authenticity in language instruction refers to the learning tasks that bridge the gap between classrooms and real life (Herrington, Reeves \& Oliver, 2014). It is an important feature of task-based language teaching (Ellis, 2003). Most materials and tasks that are designed for L2 classes are stiff that they do not reflect the real use of the target language, making it less practical in out-ofclass context. Hence, proponents of authentic language learning suggest the use of authentic materials such as magazine, novel and brochures to introduce the students to the actual way the target language is used in daily life communication. Apart from authentic materials, authentic tasks engage the students with real life issues that they can relate to in their everyday life (Ellis, 2003).

Authentic task is a highly useful language pedagogical tool. Creating a link between the classroom and real life gives a sense of relevance and meaning to the lesson which leads to greater interest and task motivation among students (Ortiz \& Cuellar, 2018). In contrast, inauthentic tasks, despite having its own values, tend to disengage students as they may find them to be inapplicable in real life. On top of that, authentic tasks - promote critical thinking as students are encouraged to demonstrate the use of meaningful knowledge and skills (Mohamed \& Lebar, 2017). Instead of copying a fixed solution prescribed by the textbook, authentic tasks challenge the students to explore a broader pool of ideas to deliver the final product. 
Collaborative tasks have been extensively studied in Malaysian educational context, especially in tertiary institutions. Rashid, Yunus and Wahi (2019) conducted a quantitative research to study the opinions of a group of undergraduate students in a Malaysian public university on a collaborative writing project done using Padlet, an interactive online tool. The collaborative nature of the task encouraged interaction among class members and lecturer and improved language accuracy through learning from their groupmates. Similarly, Aiedah and Lee (2012) studied the performance of tertiary students in collaborative tasks, and found that the students were observed to be more responsible over their learning, with more frequent consultation sessions with their instructors. Another study by Ramanair, Rethinasamy \& Misaeng (2017) on collaborative writing using a different online tool; Wiki, in tertiary learning context found similar results. The respondents reported high level of interaction between classmates and their motivation to complete the task. However, some respondents complained regarding the technical difficulties that they faced to complete the task such as connectivity issues and web browser compatibility. The respondents also noted that their lack of familiarity with the genre of the project and the system being used had added another layer of difficulties for them and they preferred a more familiar method.

Collaborative tasks are not limited to tertiary language classroom as primary and secondary school English teachers have started to incorporate them in their lessons. Lawrence and Lee (2016) investigated the usefulness of web-based collaborative writing tasks among Form 5 students in a secondary school in Malaysia and found that benefitted greatly from the higher autonomy given to them as it allowed them to develop meaningful ideas. However, the researchers found that students with low English proficiency had to rely on the teacher to make any progress in their writing. Collaborative writing has also been practiced in Malaysian primary schools. Miin, Rou and Yusus (2019) studied the effectiveness of collaborative writing activities using Google Docs among primary school students with marginal passing rate. They found that the students were highly motivated to participate in the writing activities because of its uniqueness, as the activities were different from their normal writing practice. There were also improvements in terms of sentence constructing as the weaker students learnt by imitating their classmates' sentences.

Although there are many studies on collaborative writing in different contexts, there is a lack of research conducted on pre-university students. Pre-university is a crucial phase to bridge the gap between secondary and tertiary studies; it equips students with the knowledge and skills for tertiary studies. In contrast with individual writing assessment in PT3 and SPM that they are familiar with, assessments in tertiary studies often require them to produce a written text in a group. On top of that, they have to produce texts of different genres, which vary in terms of content, linguistic features and style of writing. Hence, it is important for English classes in pre-university centres to address this need.

In the current study, the researcher studied the attitude of several pre-university students towards an authentic collaborative writing project where they had to publish a mini magazine consisting of three articles on current issues of their choice in a group of three to four students. The research objectives are; 
i. To study the perception of pre-university students on an authentic collaborative writing project;

ii. To study the benefits of an authentic collaborative writing project for pre-university students;

iii. To study the challenges of an authentic collaborative writing project for pre-university students

The perceived benefits and challenges in completing this project were noted in order to study the ways this project may contribute to their readiness for tertiary studies and any issues that may arise due to their unfamiliarity with the assessment format. It is hoped that this study will provide insights on ways to bridge the gap between secondary and tertiary studies mentioned earlier.

\section{Methodology}

The writing project was part of the continuous assessment of the students of the pre-university centre, with a weightage of $15 \%$ of their final grade. The project required them to work in groups of three to four students where they had to produce a magazine which consists of three articles. They were given five types of magazine to choose from; entertainment, sport, technology, health and social issue magazine, but they were allowed to choose any article topics that suit the magazine genre that they opted for. This project was mostly completed independently by the students with some guidance from the instructors.

Ten students who were studying in a local pre-university centre participated in the interviews. They were randomly selected from a sample of 705 students in the centre. Their English proficiency ranges from good to excellent, based on their final exam result. Three of them were from the Physical Science stream, while the other six were from the Life Science stream. They had three-hour English class per week. The details of the students are as below

\begin{tabular}{|l|l|l|l|}
\hline Student & Program & Gender & $\begin{array}{l}\text { English Final } \\
\text { Exam Result }\end{array}$ \\
\hline A & Life Science & Male & A- \\
\hline B & $\begin{array}{l}\text { Physical } \\
\text { Science }\end{array}$ & Male & A \\
\hline C & Life Science & Male & A \\
\hline D & Life Science & Female & A \\
\hline E & Life Science & Male & A \\
\hline F & Life Science & Female & A \\
\hline G & $\begin{array}{l}\text { Physical } \\
\text { Science }\end{array}$ & Female & B+ \\
\hline H & Life Science & Female & A \\
\hline I & Life Science & Female & A- \\
\hline J & $\begin{array}{l}\text { Physical } \\
\text { Science }\end{array}$ & Female & A \\
\hline
\end{tabular}


The data were elicited through semi-structured interview where all interviewees were asked the same basic questions. Semi-structured interview was chosen because it increases the comparability of responses as the respondents answered the same questions (Patton, 1980). Moreover, semistructured interview ensures that the collected data are complete for each interviewee on the topic addressed in the interview (Cohen, Manion \& Morrison, 2011). The basic questions asked to the students were;

i. How do you feel regarding the magazine assignment?

ii. What are the benefits that you gain from this assignment?

iii. What are the challenges that you face in completing this assignment?

On top of these basic questions, the researcher asked the interviewees additional questions to elicit clearer and more elaborated responses whenever necessary. The interviews were conducted during their study week, about a month after the magazines were completed and submitted. It was not conducted right after the submission as the students had other academic commitments. The interview was conducted in private at the researcher's office at a time decided based on the convenience of the respondents and the average length of each session was 10 minutes. The interviews were recorded with the respondents' consent and were transcribed by the researcher for analysis. Similar responses from different respondents were colour-coded and subsequently grouped under the same heading. The findings were presented in the next section.

\section{Findings and Discussion}

In general, all the respondents showed positive attitude towards the mini-magazine projects, despite having some hiccups when working in a group. The figure below describes the major ideas extracted from the respondents. 


\section{Overall Perception}

Interesting New Experience

High Autonomy

\section{Benefits}

Extensive reading

Personal relationships

Peer Assessment

Higher Sense of Responsibility

\section{Challenges}

Technical difficulties

Conflicting ideas

Minimal teacher input

\section{Overall Perception}

i. Interesting New Experience

Most of them said that it was an interesting project as it was a new experience as they had never done similar projects when they were in secondary school. According to Student A, B and C:

I think it was fun activity. We have experience to do a magazine so it can bea new experience for us. (Student A)

I think this magazine (assignment) is quite good. Because it gives us new experience and the idea how to develop a magazine. (Student B)

A new experience, because it's also a new type of magazine. But along the process of doing it, I had a lot of fun. (Student C)

The uniqueness of this project compared to their heavily SPM-oriented exercises in secondary school increased their interest and engagement. This finding is consistent with the previous study by Miin, Rou and Yusus (2019) that suggests the link between task uniqueness and intrinsic motivation although the research was conducted among primary school students. Thus, it can be suggested that the link between task novelty and motivation is generalisable across age.

\section{ii. High Autonomy}

The respondents also commented that they experienced greater autonomy over their project as they were allowed to make most of the major decisions such as the concept and topic of the articles on 
their own. Most respondents regarded this positively as it opened more room for creativity and freedom of expression. According to Student B, D and F:

Furthermore, for this magazine, we are free to choose our own title and what is it about...Because when we choose, we are freeto choose the title, we are free to write the essay. We can write it in our own way. (Student B)

In terms of free speech, a bit more vast topic, something more sensitive we can talk about...We don't really have format in what we do. We get to be a bit more creative. (Student D)

Because I think I can like, I can talk about things that I like instead of topics that people give me...I can express myself. (Student F)

The freedom to choose topics that were meaningful to them on a personal level seems to be an important factor that contributed to their positive feelings regarding this project, supporting the finding of the study by Lawrence and Lee (2016) that shows that high level of autonomy allows more room for meaningful ideas. Having personal interest in the topics leads to curiosity and resourcefulness, which enabled them to complete the project successfully despite their lack of experience in publishing a magazine.

Benefits of the Project

i. $\quad$ Extended Reading

When asked about the benefits of this project, almost all of the respondents agreed that it had pushed them to read extensively as they had to conduct their own research in order to find information to include in their articles. This had contributed to their knowledge on the topics that they chose. Student A, B, C, D and E commented that:

Yea, because we don't know about the AR right? My group topic is the AR in football, eh, the VAR in football. So we need to do few research about rule of VAR. (Student A)

We do readings online and we discuss among our friends about what can be added into the essay. (Student B)

We learnt new things. For example, our topic was studying about Ted Bundy, the infamous murderer, the technology and we learn... We have to do a lot of research for the content. (Student C)

Oh yes, extra reading. A lot of extra reading. Things that we just found out also. To me, among the benefits are we get to actually know a bit more thoroughly on general topics nowadays. (Student D)

I think it's fun. And because we are required to search for articles, I think that helps in knowing general knowledge. We get to know many new things, many information. (Student E)

Searching for related information is an important skill in tertiary studies. The high degree of autonomy given to the students in this project has encouraged the students to conduct their own research and read more relevant articles. This has helped the students to improve their research skills and the exposure to more reading articles can improve their language. 


\section{ii. Interpersonal Relationship}

The students noted that they had a lot of meetings to exchange ideas and to reach a mutual decision on the execution of their project. Some of them highlighted that the frequent meetings had benefitted them on a personal level by strengthening their relationship with each other. Student $\mathrm{C}$ and $\mathrm{H}$ mentioned that:

We meet up because of the magazine. We meet up very regularly and it wasn't a serious meeting, it was a fun meeting, we discuss with each other. (Student C)

We get to meet so often, we get to meet everyday I think because of the magazine, for 1 week, because we need to discuss about the design, the content and the structure of the essay. Our relationship is quite close at that time, because of the magazine. (Student $\mathrm{H}$ )

This finding is similar to the study conducted by Abdul Rashid, Yunus and Wahi (2019) and Ramanair, Rethinasamy \& Misaeng (2017) where collaborative tasks are found to boost interaction among classmates. On top of that, the present study found that this frequent interaction has improved their relationship beyond the classroom where they reported that they became closer as friends.

\section{iii. Peer Assessment}

Apart from that, the respondents said that the collaborative nature of the project allowed them to conduct peer-assessment where they checked each other's contribution to ensure minimal language errors. This contributed to better grammatical accuracy and complexity as well as text fulfilment (Storch, 2005). This will eventually contribute to the improvement of their language proficiency (Ong \& Maarof, 2013). According to Student C, G and I:

We have 3 members, one essay for each member. But at the end, we check each other's. (Student C)

Because me myself is not good in writing English essay, but with them, they provide, they check my spelling and sentence structure. (Student G)

From this magazine, I learn about teamwork, most important. I learn how to sharpen my vocabulary and grammar. We gather in the group and check the mistakes together. We check just to make sure that everything is perfect. (Student I)

iv. Higher Sense of Responsibility

Similar to Aiedah and Lee (2012), this study found that collaborative project improves students' sense of responsibility. Several respondents explained that working on the writing project as a team cultivated a sense of responsibility to produce a good piece of writing as it will affect the overall group mark. Student $E, H$ and I said that:

I feel responsible because everyone have to perform their best so we get the best results. (Student E)

I feel responsible. We divide our tasks and each person is responsible for each part. And I think I must be responsible. I must be making this part good because this part is belong to me and if I don't make it perfect, I will make the magazine worse. (Student $\mathrm{H}$ )

Because it affects other's marks if I don't do my best. (Student I)

\section{Challenges}

i. Technical Issues 
Despite showing a highly positive attitude towards this project, some respondents admitted that their lack of experience in producing an authentic genre of text i.e. magazine had caused some difficulties. They found the designing and printing process to be quite challenging. Student $A, F, G$ and I mentioned that:

Actually, for the last part, we want to print the magazine but the shop make it wrong so we have to pay more. We fight with the shop. (Student A)

The editing part. In my group, there's no one who knows how to edit. (Student $F$ )

The challenges would be printing the magazine. Because we can print in on A4 but we want to make it like a real magazine. And which we have to find a printing service that provide A3 paper. So far, in Kota Samarahan, there's only 1 place that I know of. (Student G)

For me it's the editing part because one of the limitations in that I only have the basic editing skill. And then the editing app I use. I edit using a phone instead of a computer because it's lagging. (Student I)

This finding is consistent with the finding of Ramanair, Rethinasamy \& Misaeng (2017) who studied a different type of task, which was Wiki writing. Both studies show that technical issue is a concern when students are given a task of unfamiliar genre.

\section{ii. Conflicting Ideas}

Besides the technical difficulties in designing and printing the magazine, some respondents mentioned that they had different or conflicting ideas with their group members. This caused a slight delay in completing their project. According to Student D, F, G and J:

Among the challenges were actually agreeing to an idea of a topic. (Student D)

Some of us want to talk about deep things, some of us just want to talk about the surface.

(Student F)

The editing part takes a lot of time, especially all members contribute their own design. (Student G)

The design I think because sometimes we don't agree with each other. (Student J)

However, conflicting ideas are not necessarily a negative thing as it shows that they interacted and negotiated with each other, which supports previous findings by Abdul Rashid, Yunus and Wahi (2019) and Ramanair, Rethinasamy \& Misaeng (2017). This means that the discussions are meaningful as students contributed their own ideas into the project.

iii. Minimal Teacher Instruction

On top of that, some respondents noted that they experienced difficulties at the initial stage of their project due to the minimal teacher instruction. Although these respondents showed a positive attitude towards the autonomy over their project, they commented that choosing an appropriate topic was a challenging stage. Student $\mathrm{E}$ and $\mathrm{H}$ said that:

I think it gives more freedom. But sometimes I feel too much freedom and we don't know what to choose. (Student E)

For me, for this assignment, it is a really fun activity, but it is also hard. Our group members need to find the specific title, we are talking about entertainment. And the subtopic for that. It was really hard. (Student $H$ ) 
While Lawrence and Lee (2016) found that only low proficiency students experience difficulties when given low level of guidance from the teacher, the present research shows that students with good English faced a certain level of difficulties as well. However, the responses from the students indicated that their difficulties were mostly non-linguistic.

Generally, all respondents gave positive feedback regarding the writing project. Despite experiencing some difficulties, they found the project to be interesting, engaging and motivating. They also found it to be useful for language learning and study skills acquisition.

\section{Conclusion}

This study, despite being small in scale, has demonstrated the usefulness of authentic writing tasks in a collaborative setting. The findings of this research showed that the uniqueness of the project boosts the interest of the students. They showed positive attitude towards the high autonomy that was given to them in this project as it allowed them to personalisethe product. Moreover, this project helped to equip them with collaborative and self-learning skills such as peer checking and extensive reading, which are useful for their undergraduate studies in the university. Although the perception is generally positive, the students also experienced some difficulties due to their unfamiliaritywith the design of the task, besides common interpersonal conflicts in a group assignment. Thus, continuous guidance from the instructor is still necessary, even in a project where students are given more autonomy and aims to foster independent learning. Overall, this study shows that authentic collaborative writing task can be highly beneficial for pre-university students in preparing for university studies. However, this study was conducted in a small scale with respondents with good English proficiency. They were also classmates for other subjects in live in a dormitory which may help them in collaborating for a project. The results of the current study may not be generalizable to all learning contexts. Hence, more studies should be conducted to assess the usefulness of authentic collaborative writing for students in other learning contexts such as in primary and secondary schools as well as undergraduate studies. Furthermore, future researchers can also study the extent to which similar projects are effective in target language acquisition, as the current mainly show the nonlinguistic benefits of authentic collaborative writing. Lastly, it is hoped that this study can provide teachers with a framework for an authentic collaborative project as an alternative teaching and assessment method that is not confined within the classroom.

\section{References}

Aiedah, A. K., \& Lee, K. C. (2012). Application of project-based learning in students' engagement in Malaysian Studies and English Language. Journal of Interdisciplinary Research in Education (JIRE), 2(1), 37-46.

Allen, N., Atkinson, D., Morgan, M., Moore, T., \& Snow, C. (1987). What experienced collaborators say about collaborative writing. Iowa State Journal of Business and Technical Communication, 1(2), 70-90.

Baranes, A. F., Oudeyer, P. Y., \& Gottlieb, J. (2014). The effects of task difficulty, novelty and the size of the search space on intrinsically motivated exploration. Frontiers in neuroscience, 8(317), 1-9. 
Cohen, L., Manion, L., \& Morrison, K. (2011). Research methods in education (7th ed.). New York, NY: Routledge Editors.

Ellis, R. (2003). Task-based language learning and teaching. Oxford, England: Oxford University Press.

Herrington, J., Reeves, T. C., \& Oliver, R. (2014). Handbook of research on educational communications and technology. New York, NY: Springer.

Hidi, S., \& Renninger, K. A. (2006). The four-phase model of interest development. Educational Psychologist, 41(2), 111-127.

Krause, K., Bochner, S., Duchesne, S., \&McMauch, A. (2010). Educational psychology for learning \& teaching. Melbourne, Australia: Cengage Learning Australia.

Lawrence, D., \& Lee, K. W. (2016). Collaborative writing among second language learners using Google Docs in a secondary school context. International Journal on E-Learning Practices (IJELP), 3, 63-82.

Li, M., \& Kim, D. (2016). One wiki, two groups: Dynamic interactions across ESL collaborative writing tasks. Journal of Second Language Writing, 31, 25-42.

Miin, W. P., Rou, L. Y., \& Yunus, M. M. (2019). Google Docs: Step by step sentence construction for primary school marginal passing rate pupils. Creative Education, 10(02), 237-245.

Mohamed, R., \& Lebar, O. (2017). Authentic assessment in assessing higher order thinking skills. International Journal of Academic Research in Business and Social Sciences, 7(2), 466476.

Mulligan, C., \& Garofalo, R. (2011). A collaborative writing approach: Methodology and student assessment. The Language Teacher, 35, 5-10.

Ong, P. L., \& Maarof, N. (2013). Collaborative writing in summary writing: Student perceptions and problems. Procedia - Social Behavioral Sciences Journal, 90, 599- 606.

Ortiz, S. M., \& Cuéllar, A. M. T. (2018). Authentic tasks to foster oral production among English as a foreign language learners. HOW, 25 (1), 51-68.

Ramanair, J., Rethinasamy, S., \& Misieng, J. (2017). Collaborative writing using Wiki: Tertiary students' perspectives. Electronic Journal of Foreign Language Teaching, 14(1), 84-101.

Rashid, A. A., Yunus, M. M., \& Wahi, W. (2019). Using Padlet for collaborative writing among ESL learners. Creative Education, 10(3), 610-620.

Scott, V. M., \& Fuente, M. J. D. L. (2008). What's the problem? L2 learners' use of the L1 during consciousness-raising, form-focused tasks. The Modern language journal, 92(1), 100-113.

Storch, N. (2005). Collaborative writing: Product, process, and students' reflections. Journal of second language writing, 14(3), 153-173.

Storch, N. (2013). Collaborative writing in L2 classrooms. New York, NY: Multilingual Matters.

Patton, M. Q. (1980). Qualitative Evaluation Methods. New York, NY: Sage.

Vygotsky, L. (1978). Interaction between learning and development. Readings on the development of children, 23(3), 34-41. 